\title{
PROJECTIVE ASSESSMENT OF SURGERY DRAWINGS CREATED BY CHILDREN WITH AND WITHOUT SURGERY
}

\author{
Semra SEYIS' ${ }^{1}$, Serap GÜLEÇ²*, Oya Sevcan ORAK ${ }^{2}$ \\ ${ }^{1}$ Ondokuz Mayıs University, Health Sciences Institute, 55139, Samsun, Turkey \\ ${ }^{2}$ Ondokuz Mayıs University, Faculty of Health Sciences, Nursing Department, 55139, Samsun, Turkey
}

\begin{abstract}
The study aimed to perform a projective assessment of surgery drawings created by children with and without surgery. The study had a descriptive design and included 40 children aged 7-12 years and followed in pediatric surgery clinic of a hospital in Turkey. Out of 40 children, 20 had surgery and 20 did not have surgery. Both qualitative and quantitative data collection and assessment techniques were used. Data were gathered with a child descriptive characteristics form and surgery drawings. The drawings were evaluated by using projective analysis. The projective analysis of the drawings revealed three themes, i.e., fear, perceived body integrity and surgical room image. Perceived body integrity had a significant relation with having the experience of surgery $(\mathrm{P}<0.05)$; a higher rate of the children undergoing surgery had negative perceptions about the body integrity $(50 \%)$. A lower rate of the children undergoing surgery was afraid of surgery $(45 \%)$ and a higher rate of the children undergoing surgery had a negative surgical room image (61\%), though experiencing surgery did not have relation with fear of surgery and surgical room image $(\mathrm{P}>0.05)$. In this study, the surgery drawings created by the children with and without the experience of surgery were examined through projective assessment and their perceptions about surgery were compared. The children undergoing surgery were found to have less fears but more negative perceptions about the body integrity and negative surgical room image.
\end{abstract}

Keywords: Child, Projective drawing, Perception of surgery, Pediatric surgery, Psychiatry nursing

\begin{tabular}{lll}
\hline *Corresponding author: Ondokuz Mayıs University, Faculty of Health Sciences, Nursing Department, 55139, Samsun, Turkey \\
$\begin{array}{lll}\text { E mail: dr.seraps@gmail.com (S. GÜLEÇ KESKIN) } & \text { Received: September 06, 2021 } \\
\text { Semra SEYIS } & \text { (D) https://orcid.org/0000-0001-8500-9036 } & \text { Accepted: November 04, 2021 } \\
\text { Serap GÜLEÇ } & \text { (D) https://orcid.org/0000-0001-9109-373X } & \text { Published: May 01, 2022 } \\
\text { Oya Sevcan ORAK } & \text { (D) https://orcid.org/0000-0002-7499-5077 }\end{array}$
\end{tabular}

Cite as: Seyis S, Güleç S, Orak OS. 2022. Projective assessment of surgery drawings created by children with and without surgery. BSJ Health Sci, 5(2): 174179 .

\section{Introduction}

Having an illness and hospitalization is a scary, disturbing, and unpleasant experience for children (Kortesluoma et al., 2008). Procedures performed and equipment and material used in hospital and hospital staff create the feeling of uncertainty in children. Being scheduled for surgery in addition to hospitalization may cause children to feel more stressed out and may create more physiological and psychological effects on them (Ünver and Yıldırım, 2013). Surgical interventions produce stress in children for many reasons. This stress usually presents with the signs of fear, anger, and anxiety (Dağlı et al., 2016). Children may display behavioral disorders, fears, bad temper, and sleep disorders. Although these disorders are mostly temporary, they can create continuous non-adaptability as hospital stay is lengthened (Yörükoğlu, 2008). Every child has unique perceptions, feelings, and opinions about their experiences in hospital. Therefore, children's feelings, prior experiences, perceptions about what happens and cognitive functions during their hospital stay are of great importance and should not be disregarded (İnal and Akgün, 2003). Prior experiences and perceptions of children about the hospital environment can affect their later experiences in hospitalization, adaptation to treatment and hospital, and communication with health staff (Ünver and Yıldırım, 2013). It has been reported in the literature that hospitalization leads to several problems in children and that they perceive interventions performed in hospital as a punishment for their misbehavior (Gönener and Görak, 2009; Gündüz et al., 2016).

It is important that nurses must use not only verbal but also nonverbal techniques to evaluate perceptions of children during hospitalization. Nurses can create an artistic environment and utilize several activities including drawing, music, painting and shaping playdough and clay (Orak, 2017). Drawing is not only a creative and artistic communication technique but also a data collection tool allowing a projective assessment. It also constitutes a nonverbal communication environment and allows individuals to express what they feel easily. Therefore, it is emphasized in the literature that drawing can be employed as a diagnostic tool to identify children having difficulty in establishing verbal communication due to their young age or personality features. Children can reflect what psychological problems they experience in their drawings (Yolcu, 2004). Several significant elements revealing children's lives purely, plainly, and directly in drawings include 
symbols, lines and marks acquired through perceptions (Artut, 2004). If children are provided an opportunity to use a material, colors, forms and shapes suitable for their abilities, they show their wishes and fears in addition to their opinions and feelings (Ayaydı, 2011). Hospitalized children do not know much about why they have been hospitalized and why they have become ill. Depending on their developmental characteristics, children may not understand everything about their illnesses completely and fill in the gaps in their minds with fantasies (Beytut et al., 2009). It should be pointed out that children do not have a fully developed perception and display a continue change in this process, vary in their perceptions and reactions regarding a disease depending on their chronological age and developmental characteristics. They also have physical, physiological and psychological features different from adults. For these reasons, it is important to determine perceptions of the children hospitalized and undergoing surgery about hospital, interventions, and surgeries by using verbal and nonverbal techniques to reveal their care needs and to offer individualized care (Beytut and Solak, 2009). The art of pediatric nursing is based on utilization of knowledge and skills individualized for each child. Children and nurses mostly meet for care practices. Art originates from subjective feelings of individuals, and art and opinions of children and nurses about art can be effectively utilized in primary nursing practices. A therapeutic play, projective drawing is one of the practices reflecting the artistic aspect of pediatric nursing. Pediatric nursing requires theoretical knowledge and skills regarding every aspect of child health (Çavuşoğlu, 2011). Drawings considered as the reflection of children's inner world reveal their interpersonal relationships, emotional problems, disappointments, fears, expectations and worries and help to understand them. The aim of the present study was to make a projective assessment of surgery drawings created by children with and without surgery.

\subsection{Questions of Research}

- What are the operated children's perceptions of surgery?

- What are the perceptions of surgery in children without the experience of surgery?

- Is there a relation between having surgery and perceptions of surgery?

\section{Material and Methods}

\subsection{Study Design}

This is an art-based descriptive study employing qualitative and quantitative data collection tools and evaluation methods (Dotson, 2007).

\subsection{Sample}

This study was conducted with children who received inpatient treatment in the pediatric surgery service of a hospital in Turkey. The data of the research were collected between 15 March and 30 May 2018. Among the children who were in the clinic between these dates, the first 40 children who met the inclusion criteria were included in the study (20 children with surgery experience; 20 children without surgery experience).

2.2.1. Criteria for admission to the study for children who have undergone a surgical experience

- Between the ages of 7-12,

- In the post-operative period,

- Not have early postoperative complications,

- Do not have symptoms that will prevent participation in the research,

- Have stable vital signs,

- At least 24 hours after the operation,

- Willing to participate in the study,

- Children who were approved by their parents to participate to the study were included in the research.

2.2.2. Admission criteria for children with no surgical experience

- Between the ages of 7-12,

- In the pre-operative period,

- Have no previous surgical operation experience,

- Have no pain,

- Do not have symptoms that will prevent participation in the research,

- Have stable vital signs,

- Willing to participate in the study,

- Children who were approved by their parents to participate to the study were included in the research.

\subsection{Data Collection}

Data collection was performed by utilizing a child descriptive characteristics form and surgery drawings.

\subsubsection{Child descriptive characteristics form}

The child descriptive characteristics form was created by the researcher in light of the literature and was composed of seven questions about socio-demographic features of the children aged 7-12 years like age, gender, number of siblings, whether they were hospitalized before, whether their siblings were hospitalized before, prior diseases and prior surgeries (Artut, 2004; Kortesluoma et al., 2008; Beytut et al., 2009).

\subsubsection{Surgery drawings}

Projective picture assessment was used to evaluate children's perceptions of surgery. According to the psychoanalytic theory, children reflect their unconscious wishes and fears in their drawings secretly and symbolically. This suggests that the drawings created by children can be employed to reveal their moods (Yavuzer, 2007). Drawing is commonly utilized as a data collection tool in education and psychology to uncover feelings and opinions of children (Okyay, 2008). In the present study, the children voluntarily accepting to participate in the study and to draw a picture were invited to the playroom. They were given drawing paper and crayons in 12 different colors and were asked to draw a picture of surgery (Figure 1). The children were 
told that they could draw it as they liked. After they completed drawing the picture, they were asked to talk about it. The researcher took notes of her observations during picture drawing and the interview notes while the children were talking about their pictures. The projective analysis of the pictures with the notes taken were made by two mental health specialists having education about projective testing
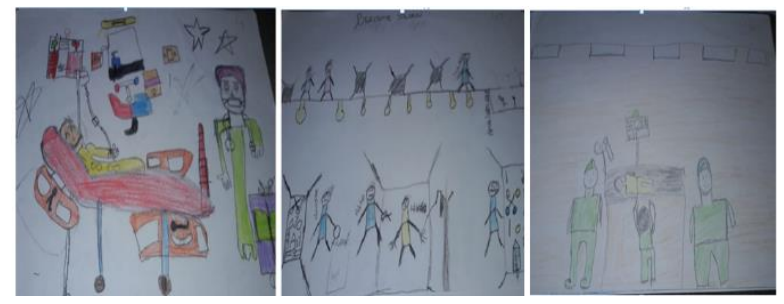

Figure 1. Examples of the surgery drawings created by the children.

\subsection{Data Analysis}

Data obtained from each child were kept in files separately. Each file contained information about descriptive characteristics, the surgery drawing, and the notes kept about the researcher's observations and what children talked about their drawings. The projective assessment of the drawings was made by using a coding list for perceptions about surgery based on expert opinions. The coding list included the order in which the objects have been drawn, the color(s) predominantly used, the location of the drawing on the paper, the size and direction of the human figures, features of the body parts, exaggerated figures, other objects drawn and their features. The elements in the drawings were coded and their projective analyses together with the notes kept by the researcher were made by two experts. The drawings created by the children experiencing surgery and those not experiencing surgery were evaluated in terms of their perceptions about surgery. The children's perceptions about surgery were grouped under three themes, i.e., fear, perceived body integrity and surgical room image. Descriptive characteristics and categories about perceived surgery projections were converted into quantitative data by using SPSS 21.00. Obtained quantitative data were analyzed with descriptive statistics (numbers and percentages).

\section{Results}

Out of 40 children included in the study, 58.5\% were aged $10-12$ years, $57.5 \%$ were male and $80 \%$ had at least one sibling. Fifty percent of the children had a prior hospitalization (Table 1).

Table 1. Socio-demographic features of the children

\begin{tabular}{lccc}
\hline Features & & $\mathrm{n}$ & $\%$ \\
\hline \multirow{2}{*}{ Age Groups (year) } & $7-9$ & 17 & 42.5 \\
& $10-12$ & 23 & 58.5 \\
\multirow{2}{*}{ Gender } & Female & 23 & 57.5 \\
\multirow{3}{*}{ Number of Siblings } & Male & 17 & 42.5 \\
& Yes & 32 & 80 \\
Prior Hospitalization & No & 8 & 20 \\
& Yes & 20 & 50 \\
& No & 20 & 50 \\
\hline
\end{tabular}

The pictures created by the children were examined in terms of their drawing features, the notes kept about the researcher's observations and what the children talked about their pictures by two experts using content analysis. The analysis revealed three themes including fear, perceived body integrity and surgical room image and obtained findings were converted into quantitative data (Table 2). In addition, the relation between having surgery and fear about surgery, perceived body integrity and surgical room image was examined (Table 2).

Table 2. The relation between the experience of surgery and fear, perceived body integrity and surgical room image in the drawings

\begin{tabular}{|c|c|c|c|c|c|c|}
\hline & & \multicolumn{2}{|c|}{$\begin{array}{l}\text { Children with Surgery } \\
\qquad n=20\end{array}$} & \multicolumn{2}{|c|}{$\begin{array}{c}\text { Children without } \\
\text { Surgery } \\
n=20\end{array}$} & \multirow[t]{2}{*}{ Test and p Values } \\
\hline & & $S$ & $\%$ & $\mathrm{~S}$ & $\%$ & \\
\hline \multirow{3}{*}{ Fear } & Yes & 9 & 45.0 & 13 & 65.0 & $\chi^{2}=1.628$ \\
\hline & No & 11 & 55.0 & 7 & 35.0 & $\mathrm{P}=0.202$ \\
\hline & Positive & 10 & 50.0 & 16 & 80.0 & $\chi^{2}=4.054$ \\
\hline Perceived Body Integrity & Negative & 10 & 50.0 & 4 & 20.0 & $\mathrm{P}=0.044$ \\
\hline \multirow{2}{*}{ Surgical Room Image } & Positive & 9 & 40.9 & 13 & 59.1 & $\chi^{2}=1.628$ \\
\hline & Negative & 11 & 61.1 & 7 & 38.9 & $\mathrm{P}=0.202$ \\
\hline Total & & 20 & 100 & 20 & 100 & \\
\hline
\end{tabular}

The theme fear appeared in $45 \%$ of the children having surgery and in $65 \%$ of the children without surgery. However, the fear of surgery did not have a significant relation with having surgery (Table 2; P>0.05). Fifty percent of the children having surgery and $20 \%$ of the children without surgery had a negative perception about the body integrity. The perceived body integrity had a significant relation with the experience of surgery (Table 2; $\mathrm{P}<0.05$ ). Sixty-one percent of the children experiencing surgery and $39 \%$ of the children not 
experiencing surgery had a negative surgical room image. However, the relation between the surgical room image and the experience of surgery was not significant (Table 2 ; $>0.05$ ).

\section{Discussion}

In the present study, a higher rate of the children not having surgery were afraid of surgery compared to those having surgery. However, there was not a significant relation between these variables ( $\mathrm{P}>0.05$; Table 2$)$. It is reported in the literature that fear is a sudden unwanted emotional behavior or reaction against a certain real or unreal situation and danger. Fears experienced by children vary with their age. Except for physical examinations, painful procedures like vaccination, collection of blood samples and injections are performed in hospitals. Children may have to be hospitalized for their treatment in addition to day care procedures and even may have to be operated. They may lead to fear and anxiety in children (Gündüz et al., 2016). However, in a study by Ayan and Öztürk Şahin (2019) therapeutic play offered to children hospitalized for surgery was reported to reduce anxiety and fear due to the procedure. Tsai et al. (2013) investigated the effect of therapeutic play on the fear resulting from radiotherapy and found out that therapeutic play decreased this fear, increased the children's cooperation and improved their communication with health staff during their treatment process. In another study, the children whose parents had an education level lower than high school were found to experience more fear of hospital than other children. Also, the children not afraid of hospital had medical toys at home and were more frequently informed about hospital by their parents $(\mathrm{P}<0.05)$. Besides, rather than performing injections, not informing children before performing injections by health staff was a significant factor causing the fear of hospital in children. The health staff's communicating with and rewarding children was found to reduce the fear of hospital (Gündüz et al., 2016). In a study by Çamur (2017) education and therapeutic play combined with education significantly decreased anxiety and fear in children after surgery compared to the control group Justus et al. (2006) reported that the children offered a preoperative preparation program recovered more quickly and less frequently experienced emotional problems like separation anxiety and sleeplessness. A study by Mete (2018) on 8-12-year-old children hospitalized for surgery and not having a prior experience of surgery showed that $65 \%$ were given information about the hospital environment and $76.6 \%$ were given information about surgery. These children were found to have fewer thoughts creating anxiety. Mete (2018) noted that the faces in the pictures drawn by the children before surgery did not have a mark representing an expression, but that the faces in the pictures drawn after surgery had a smile and were happier, which suggested a decrease in anxiety in the children. In the present study, the lower rate of the theme of fear in the children having surgery can be explained by their possible experiences reducing their fear before and during the procedures (effective communication and offering information). Fear refers to a sudden unwanted emotional behavior or reaction in case of a certain real or unreal situation or danger. In the current study, the projective picture drawing test was administered after surgery. Since the threat causing fear disappeared, the fear felt by the children might have decreased.

Perceived body integrity had more negative features in the drawings created by the children having the experience of surgery. Also, the relation between the experience of surgery and perceived body integrity was significant (Table 2; $\mathrm{P}<0.05$ ). Children aged 6-12 years have concerns about the body image in the preoperative period. Besides, they have fears and worries about how long surgery will last, whether they will stay awake and what they will look like after surgery (Smith and Dearmun, 2006). The steps of surgical procedures should be explained to children by playing games with them on a mannequin or by using visual aids (video, posters and brochures) to increase their cooperation. There is evidence in the literature that talking to small children through puppets and allowing children aged over 9 years to touch and examine the equipment used in hospital and offering them information about the procedure through visual aids help to decrease their fears about disruption of the body integrity. Projective picture drawing is a therapeutic play recommended to understand the feelings of the children aged 7-12 years about their body integrity/body image (Mooney, 1997; Price and Gwin, 2008; Çavuşoğlu, 2011). To the best of our knowledge, there have not been any studies examining the relation between experiencing surgery and perceived body integrity in children. However, it is reported that the negative change in the child body, disruption of the body and resultant pain and discomfort are considered as the factors causing stress (LeRoy et al., 2003; Sadhasivam et al., 2009). Perceived body integrity can change in children before and after surgery. All physical diseases and disorders can lead to anxiety about the loss of the body integrity in children and can trigger negative attitudes and behavior towards themselves.

The children having the experience of surgery had a more negative surgical room image, but the relation between the experience of surgery and surgical room image was not significant (Table 2; P>0.05). Regardless of their age and development, all children have physical, emotional and cognitive needs while getting prepared for surgery. Therefore, the nursing interventions directed towards children before and during hospitalization and before surgery can provide great benefits in terms of reduction of anxiety (Altay, 2008). In a quasiexperimental study performed with children aged 5-12 years, scheduled to have daycare surgery and not taking anxiolytic medications, the children in the intervention group were taken to a special game room for 15 minutes, 
while the children in the control group set in the waiting room. The intervention group participating in a game activity while waiting for surgery were found to have a lower level of anxiety. It was concluded that the environment provided for the children in the hospital affected their surgical room image (Weber, 2010). In a study on children aged 4-11 years in a university hospital in Finland, the children were asked to draw a picture of an ideal hospital. The pictures were found to contain the hospital environment in general, but nurses and parents occupied less space (Pelander et al., 2007). Kain et al. (2000) offered a program involving behavioral methods like therapeutic play and introduction of the hospital and the surgical room to children aged over 6 years 5-7 days before surgery and discovered that the program was effective in reduction of anxiety in the children. Medical toys can be utilized to show changes likely to appear in perceived body integrity and feelings in children. Playing with these toys both help to demonstrate medical and surgical procedures and where an incision or edema will appear after surgery and allow children to express their feelings. The language used during the play is of importance. For example, the words incision, edema and organ can be substituted for opening, swelling and a special part of the body respectively. Children can be told that they will feel discomfort instead of pain. The items that can be used in a therapeutic play includes dolls, toy animals and puppets and the therapeutic play will help children to overcome the negative feelings about the body integrity (Justus et al., 2006; Altay, 2008). The American Academy of Pediatrics and the American Pain Society (2001) reported that pain and stress should be minimized even in minor interventions like peripheral vein cannulation (Committee on Psychosocial Aspects of Child and Family Health, 2001). In the current study, a higher rate of the negative surgical image in the children with the experience of surgery can be due to a lack of appropriate physical conditions in the hospital where the study was conducted.

\section{Conclusion}

In light of the results of the study, perceived body integrity is related to the experience of surgery. The children experiencing surgery had a higher rate of a negative perception of body integrity. Besides, the children experiencing surgery had a lower rate of fear but had a higher rate of a negative surgical room image. Data were collected from the children having surgery after the surgical procedure. However, it is necessary to determine feelings such as fear before surgery. It can be recommended that projective drawing is utilized before surgery in further studies. Nurses could utilize drawing to elicit data that cannot be expressed verbally to communicate with children. They could also offer education by introducing medical material and employing stories and creative drama to reduce fear in children. The drawings created by children are important in that they reveal emotional changes in children before surgery. They give hints at fears, perceptions, fantasies and misunderstandings of children. They also give information to nurses about emotions and support needs of children. Besides, the assessment of the drawings can guide nurses in care provision to help children to cope.

\section{Author Contributions}

Concept: SS and SG, Design: SS, SG and OSO, Supervision: SG and OSO, Data collection and/or processing: SS, Data analysis and/or interpretation: SG and OSO, Literature search: SS, SG and OSO, Writing: SS, SG and OSO, Critical review: SS, SG and OSO.

\section{Conflict of Interest}

The authors declared that there is no conflict of interest.

\section{Ethical Approval/Informed Consent}

Before the study was initiated, ethical approval was obtained from Ondokuz Mayis University Ethical Committee of Clinical Research (approval date: 13 April 2018; approval number: 15374210-622.03-E.8735). Written permission was also obtained from Ondokuz Mayıs University Health Research and Practice Centre (15374210-622.03-E.8735).

\section{References}

Altay NC. 2008. Preoperative preparation for children. J Hacettepe Univ Fac Nurs, 15(2): 68-76.

Artut ÖGK. 2004. An investigation on children's development level of drawing during pre-school illustration education. Çukurova Univ J Soc Sci Inst, 13(1): 223-234.

Ayaydın A. 2011. Art and drawing as a game in child development. Electronic J Soc Sci, 10(37): 303-316.

Ayan G, Öztürk Şahin Ö. 2019. The effect of education given to children through therapuetic games during the preoperative period on their anxiety and fear levels. MSc Thesis, Karabuk University, Institute of Health Sciences, Karabük, Turkey, pp: 99.

Beytut DŞ, Bolışık B, Solak U, Seyfioğlu U. 2009. A study of the influences of hospitalization on children through drawing as a projective method. Maltepe Univ J Nurs Sci Art, 2(3): 35-44.

Committee on Psychosocial Aspects of Child and Family Health. 2001. The assessment and management of acute pain in infants, children, and adolescents. Pediatrics, 108(3): 793 797. DOI: $10.1542 /$ peds.108.3.793.

Çamur Z. 2017. The effect of parental participation in the care of hospitalized child on parental satisfaction and anxiety of both parent and child. MSc thesis, Adnan Menderes University, Institute of Health Sciences, Aydın, Turkey, pp: 110.

Çavuşoğlu H. 2011. Çocuk sağlığı ve hemşireliği. Sistem Offset Printing House, Ankara, Turkey, 10(1): 19-20.

Dağlı S, Demirci M, Kavalcı A, Kol N, Şahin E, Uyanık E. 2016. The effects of informing the children undergoing day surgery and their families about the surgery on preoperative anxiety and postoperative behavioral changes. URL: http://tip.baskent.edu.tr/kw/upload/464/dosyalar/cg/semp ozyum/ogrsmpzsnm14/14.S14.pdf (June 20, 2021).

Dotson ML. 2007. Educational criticism, a form of arts-based educational research for studying teachers. J Ethnograp Qualit Res, 1: 11-20.

Gündüz S, Yüksel S, Aydeniz GE, Aydoğan RN, Türksoy H, Dikme 
İB, Efendiler İ. 2016. Factors affecting hospital phobia in children. J Child Health and Diseas, 59(4): 161-168.

Gönener D. 2009. Interaction of informing situations of school age children about hospital and disease with sources of concern. Gaziantep Med J, 15(1): 41-48.

İnal S, Akgün M. 2003. Terapotik communication of hospitalization child. J Anatolia Nurs Health Sci, 6(2): 67-76.

Johnson BH. 1990. Children's drawings as a projective technique. Pediatric Nurs, 16(1): 11-17.

Justus R, Wyles D, Wilson J, Rode D, Walther V, Lim-Sulit N. 2006. Preparing children and families for surgery: Mount Sinai's multidisciplinary perspective. Pediat Nurs, 32(1): 3544.

Kain ZN. 2000. Perioperative psychological issues in children. American Soc Anesthesiol, 64(8): 123-127.

Kortesluoma RL, Punamäki RL, Nikkonen M. 2008. Hospitalized children drawing their pain: the contents and cognitive and emotional characteristics of pain drawings. J Child Health Care, 12(4): 284-300. DOI: 10.1177\%2F1367493508096204.

LeRoy S, Elixson EM, O’Brien P, Tong E, Turpin S, Uzark K. 2003. Recommendations for preparing children and adolescents for invasive cardiac procedures: a statement from the American Heart Association Pediatric Nursing Subcommittee of the Council on Cardiovascular Nursing in collaboration with the Council on Cardiovascular Diseases of the Young. Circulation, 108(20): 2550-2564. DOI: 10.1161/01.CIR.0000100561.76609.64.

Mete S. 2018. Emotional appearance reliability and validity scale for children in Turkey. MSC Thesis, Pamukkale University Institute of Health Sciences, Department of Nursing, Denizli, Turkey, pp: 96.

Mooney KM. 1997. Perioperative management of the pediatric patient. Plastic Surg Nurs, 17(2): 69-75.

Okyay L. 2008. Comparison of family pictures of 6 age group children in terms of sociocultural variables and behavioral problems. Master Thesis, Trakya University, Institute of
Social Sciences, Edirne, Turkey, pp: 128.

Orak OS. 2017. Communicating in special situations. The secret of life is communication. Nobel Medical Bookstore, Ankara, Turkey, No: 4066028.

Orak OS, Tunç E, İren İ, Aksöz M. 2020. Psychosocial problems and unfulfilled care needs of hospitalized children as perceived by their parents. Middle Black Sea J Health Sci, 6(1): 83-91. DOI: $10.19127 / \mathrm{mbsjohs.704478.}$

Pelander T, Lehtonen K, Kilpi HL. 2007. Children in the hospital: Elements of quality in drawings. J Pediatr Nurs, 22(4): 333341. DOI: 10.1016/j.pedn.2007.06.004.

Price DL, Gwin JF. 2008. Pediatric Nursing: 10. Edition. An Introductory Text, China, pp: 233.

Sadhasivam S, Cohen LL, Szabova A, Varughese A, Kurth CD, Willging P. 2009. Real-time assessment of peri operative behaviors and prediction of perioperative outcomes. Anesth Analg, 108: 822-826. DOI: 10.1213/ane.0b013e318195c115.

Smith J, Dearmun A. 2006. Improving care for children requiring surgery and their families. Pediatr Nurs, 18(9): 3033.

Tsai YL, Tsai SC, Yen SH, Huang KL, Mu PF, Liou HC, Chen YW. 2013. Efficacy of therapeutic play for pediatric brain tumor patients during external beam radiotherapy. Child's Nervous Syst, 29(7): 1123-1129. DOI: 10.1007/s00381-013-2099-3.

Ünver S, Yıldırım M. 2013. Approach to pediatric patients during surgical interventions. J Curr Pediatr, 11(2): 128-133.

Weber FS. 2010. The influence of playful activities on children's anxiety during the preoperative period at the outpatient surgical center. J Pediatr, 86(3): 209-214.

Yavuzer H. 2007. Boy with pictures. Remzi Publishing House, Istanbul, Turkey, pp: 184.

Yolcu E. 2004. Art Education Theories and Methods. Nobel Publishing House, Ankara, Turkey.

Yörükoğlu A. 2008. Children's Mental Health. Free Publications, Istanbul, Turkey, pp: 248. 